\title{
Erratum zu: Kollektive professionalisierungsprozesse in der Frühen Bildung - Entwicklung des Mandats, der Lizenzierung und der beruflichen Mobilität im Zeitraum 1975 bis 2018 in Westdeutschland
}

\author{
Mariana Grgic
}

Online publiziert: 26. Juli 2021

(C) Der/die Autor(en) 2021

\section{Erratum zu:}

Köln Z Soziol 2020

https://doi.org/10.1007/s11577-020-00667-2

Der Artikel Kollektive Professionalisierungsprozesse in der Frühen Bildung - Entwicklung des Mandats, der Lizenzierung und der beruflichen Mobilität im Zeitraum 1975 bis 2018 in Westdeutschland von Mariana Grgic wurde ursprünglich Online First ohne „Open Access“ auf der Internetplattform des Verlags publiziert. Nach der Veröffentlichung in Bd. 72 Supplement 1 pp. 197-227 hatten sich der Autor für eine „Open Access“-Veröffentlichung entschieden. Das Urheberrecht des Artikels wurde deshalb in () Der/die Autor(en) 2021 geändert.

Funding Open Access funding enabled and organized by Projekt DEAL.

Open Access Dieser Artikel wird unter der Creative Commons Namensnennung 4.0 International Lizenz veröffentlicht, welche die Nutzung, Vervielfältigung, Bearbeitung, Verbreitung und Wiedergabe in jeglichem Medium und Format erlaubt, sofern Sie den/die ursprünglichen Autor(en) und die Quelle ordnungsgemäß nennen, einen Link zur Creative Commons Lizenz beifügen und angeben, ob Änderungen vorgenommen wurden.

Die in diesem Artikel enthaltenen Bilder und sonstiges Drittmaterial unterliegen ebenfalls der genannten Creative Commons Lizenz, sofern sich aus der Abbildungslegende nichts anderes ergibt. Sofern das betreffende Material nicht unter der genannten Creative Commons Lizenz steht und die betreffende Handlung

Die Online-Version des Originalartikels ist unter https://doi.org/10.1007/s11577-020-00667-2 zu finden.

Mariana Grgic $(\bowtie)$

Deutsches Jugendinstitut

Nockherstr. 2, 81541 München, Deutschland

E-Mail: grgic@dji.de 
nicht nach gesetzlichen Vorschriften erlaubt ist, ist für die oben aufgeführten Weiterverwendungen des Materials die Einwilligung des jeweiligen Rechteinhabers einzuholen.

Weitere Details zur Lizenz entnehmen Sie bitte der Lizenzinformation auf http://creativecommons.org/ licenses/by/4.0/deed.de. 